\title{
Research Paper: Collaboration of Patients With Mobility Disabilities in Caring: Conceptual Analysis
}

\author{
Azam Saei ${ }^{1,2^{*}}$, Abolfazl Rahimi ${ }^{1,2}$ \\ 1. Department of Medical Surgery, Faculty of Nursing, Baqiyatallah University of Medical Sciences, Tehran, Iran. \\ 2. Behavioral Sciences Research Center, Baqiyatallah University of Medical Sciences, Tehran, Iran.
}

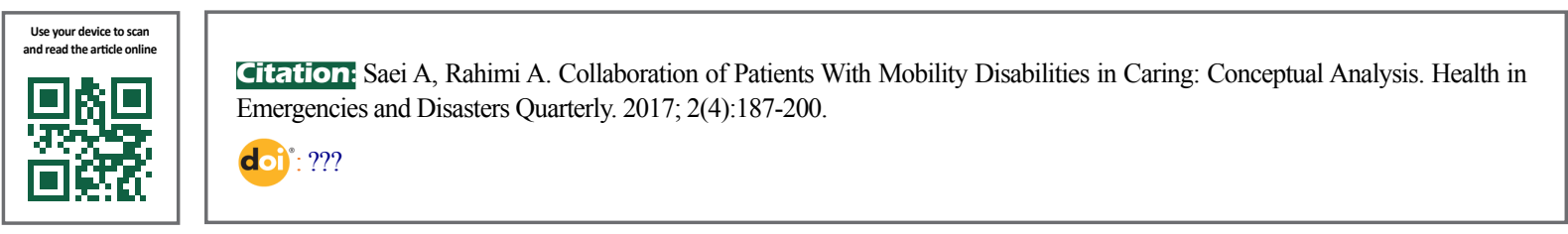

Article info:

Received: 17 Mar. 2017

Accepted: 01 Jun. 2017

\section{Keywords:}

Concept analysis, Collaboration in caring, Orthopedic injured, Traffic accidents

\section{ABSTRACT}

Background: Collaboration of patients in caring is regarded as a gold standard in professional care associated with modern nursing. Considering the complexity of the concept, it is imperative to analyze caring of patients with motor disability caused by traffic accidents.

Materials and Methods: This is a qualitative study to analyze the concept of collaboration in caring for traffic casualties using a hybrid model in three stages. In the first stage, to conduct a systemic review, a literature search was performed using databases such as Blackwell, CINAHL, MEDLINE, and Elsevier with the keywords: Collaboration in caring and orthopedic victims of traffic accidents. The literature search resulted in 110 related reviews up to 2016 . In the second stage or field stage, for the importance of collaboration in caring for traffic casualties, 7 traffic victims and 3 nurses were interviewed and data were analyzed by content analysis. Finally, in the third stage, an overall analysis was performed according to the findings in previous stages.

Results: Combining the results of reviews and findings of field study, we obtained 87 codes, 14 subcategories, and 5 categories ("organizational factors in sharing information and knowledge", "promoting a sense of responsibility in patient", "patient empowerment for health promotion", "mutual trust", and "hypersensitivity to active engagement to return to normal life") in content analysis.

Conclusion: Recognizing the concept of collaboration of patient with motor disability in caring from the orthopedic viewpoint, managers and nurses will be able to plan and execute management and educational activities according to the insight obtained from scientific findings to provide suitable conditions in this regard.

\footnotetext{
* Corresponding Author:

Azam Saei, PhD

Address: Department of Medical Surgery, Faculty of Nursing, Baqiyatallah University of Medical Sciences, Tehran, Iran.

E-mail:azam.saei@gmail.com
} 


\section{Introduction}

rauma in modern industrial societies is an important topic for discussion in a large

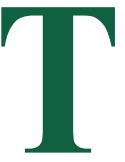
number of countries. There is little doubt that the most common cause of death and physical impairment leading to disability among the youth is attributed to different forms of trauma. There is growing incidence of trauma with the development of industrial societies [1]. Trauma is now formally known as one of the most important and most common risk factor [2, 3]; statistics indicate that most $(41.3 \%)$ of the unintentional injuries are related to traffic trauma [4]. In recent years, there have been numerous reports of serious traffic accidents in Persian Gulf states, including Iran [3], with considerable mortality and morbidity. It is obvious that mortality and morbidity caused by traffic trauma bring significant social and economic damages, many of which can be avoided [2].

Trauma and mobility problems caused by traffic accidents are important common health problems of the society. Hospitals in Iran have always been confronted with a large population of traumatic patients with mobility problems, for which a huge financial budget is needed [2]. Despite extensive efforts to provide health care services to traffic casualties to improve their life quality, there are still many defects in the quality of services provided to them. Therefore, it is really necessary to bring about changes and to use new strategies to promote the life quality of the traffic accident victims $[4,5]$

To plan for such a strategy, it is necessary not only to have a lower cost of living and decreased burden of injuries on individuals and society but also to help them to have independent lives with less dependency to care services and more responsibility towards their own health $[6,7]$. Challenges in caring for victims of traffic accidents will be responded through planning and implementation of different models of caring based on "patient involvement in the care process and his/her collaboration in treatment". By implementation of this important principle, the patient would recognize his/her own priorities and preferences, which would help him/ her to comply with the injury, to solve his/her problems, and to gain necessary skills in this context [8].

Customer-focused and humanistic strategies in health care system are placed instead of traditional ideas and approaches - which consider patient as a passive and receptive for decisions - because of improvements in medical sciences, whose implementation promotes health care system. Patients are actively involved in their care procedures nowadays; since paying attention to the information-communication health programs, as well as involvement and collaboration of patient in his/her care are among the basic areas in the process of improving individual health [9].

At the same time, the participation of a patient in his/ her health care in patient oriented caring is known as a basic concept in developing life quality [10]. Since patient oriented caring means providing respectful care and responding to patients' preferences, needs, and values, the emphasis is on the role of "involved patient" with active involvement in decision-making in relation to their own conditions [10], in patient oriented approach [9]. The idea of patient collaboration is the foundation and basis of modern nursing paradigm, and with its increasing application in nursing, the focus is now on valuing the humanity and individuality of each patient [9]. Studies related to collaboration in caring point to improving relationships between patients and health care providers. Collaboration of patients in caring can lead to developing treatment plans [10], which are not only the patients' legal right, but also a gold standard for health care systems. Therefore, the emphasis is on interdisciplinary treatment cares, and different specialties to try for implementation of such collaborations $[9,10]$.

Collaboration of patients with mobility disability in caring is considered an interdisciplinary phenomenon related to socio-cultural background, which plays an important role in recovery of patients with motor problems caused by traffic accidents to make them ready to return to normal life in society [11]. Discovery of different aspects of collaboration of patients in health care and patient oriented initiatives have been the focus of several studies, whose recognition helps greatly in providing more efficient services [10]. From another point of view, providing health care services and collaboration is an interactive process formed while communicating with others [11]. A few studies in Iran indicate that patients face major obstacles to participate in health care because of noncollaborative organizational tradition in the hospitals and poor intrasectoria cooperations [9]; and many of the patients face enormous challenges due to lack of collaborative insight in caring and defects in selfcaring knowledge [10].

Collaboration of patient has inherent dimensions in addition to abstract and philosophical ones. In other words, it is an ideal performance as inherent philosophy of nursing that the patients and injured in traffic accidents should participate in all responsibilities related to planning, im- 
plementation, and evaluation of their own care for moving [11, 12]. Utilizing and increasing the collaboration of patients in caring have improved the responsibility and commitment of patients towards promoting behaviors that facilitate their health in caring, rehabilitation, and recovery [13]. Despite the great importance of this concept in nursing profession, and extensive daily use of the term, collaboration of patients with motor disability is still very vague and complex concept. In fact, lack of clarity may result in improper and low-value use of the concept that may affect negatively to the health care staffs and patients for motor cares in the area of traffic accidents, and consequently create ambiguity in the roles of the patients and nurses in nursing care [14]. Therefore, it is necessary to recognize and define the concept, and patient's collaboration needs to be an important parameter to maintain an individual's health in future.

Studies regarding the importance of the role of collaboration of traffic accident patients in rehabilitation and motor care are very few in Iran. Therefore, this very study seeks to clarify the concept of collaboration of orthopedic patients in the area of rehabilitation and care. Clarification of the concept will not only help in better understanding of the concept, and identifying the ways nurses can help the patients with traffic accidents to participate in their own healthcare and motor rehabilitation, but will also make it possible to define the amount of collaboration of patients by explaining the dimensions and specifications of the concept. After all, the injured have the right as a human being to be involved in caring for themselves, and to decide for their treatment if they are knowledgeable enough and it is possible. Therefore, there has to be a good substitute for dependency and passivity of the traffic victims.

It is very important to have deep interpersonal interactions in order to help patients while in rehabilitation or motor care period; however, in clinical performance, collaboration of patient is not properly possible [11]. Presently, there are some studies about collaboration of patients, but most of them are related to collaboration in chronic disease care [15], collaboration of vulnerable elderly patients in hospital [16], collaboration of patients with chronic heart failure in clinics [17], and active collaboration for self-empowering of AIDS patients [18]. Till now, there is no specific study related to collaboration of patients in mobility care and rehabilitation after traffic accident; and the existing texts lack naturalistic observations and interventions [14] and are only narrations told by patients. At the same time, these narrations provide a context to understand the way of collaborations in areas with little knowledge [13]. In light of these facts, it is recommended to review qualitative studies to have a better understanding about dynamic behavior of collaboration in caring [14] and to do research to know how to use research resources, facilities, and capabilities to improve collaboration in mobility care and rehabilitation of such patients. The necessity of collaboration in caring and in mobility rehabilitation is a key factor in promoting health, compatibility, and self-management in orthopedic victims of traffic accidents, although any documentation regarding such concept is lacking in Iran. The present study was undertaken to eliminate any such ambiguity or complexity related to the concept.

\section{Materials and Methods}

In this study, hybrid model was used to analyze the meaning of collaboration of orthopedic victims of traffic accidents for mobility care. Hybrid model is one of the methods for conceptualization, development of concept, and theory improvement. The model uses an approach to improve the concept to combine theoretical and experimental studies together. Since hybrid method illustrates overall visions in clinical action, it has a specific application in important phenomena of nursing [19]. This model consists of three stages: theoretical (literature review), field work (interview, observation ...), and final analysis [20]. Theoretical stage: This stage is highly theoretical, yet derived from a clinical experience. In other words, this stage includes a complete concept in nursing and a basic definition. When the concept is chosen, a thorough browsing of all articles should be started and existing definitions related to the basic one should be compared and highlighted in order to be ready to go to the fieldwork stage.

Fieldwork stage is somewhat overlapping with the first stage, with more emphasis on experimentality of the process. In this stage, qualitative data are gathered for more comprehensive analysis of the concept. Thorough browsing of all articles, started in the previous stage, will continue in this stage too. Additionally, this review will act as a base for comparing the data gathered through the fieldwork. Final analysis: This stage combines theoretical analysis to insights obtained from experimental observations and report findings. Herein, use of an analytical approach helps to summarize the analysis and provide some suggestions to redefine the concept. Comparison of the results and giving them some meanings together with the review of theoretical stage and final fieldwork make the final stage [21]. Hybrid method is used here to explain "the meaning of collaboration in mobility care for victims of traffic accidents" which consists of the following stages: 


\section{Theoretical stage}

It aims to develop a proper context for deep analysis and redefinition of the concept for next stages. At the end of this stage, the operational definition has been explained in order to be used for fieldwork stage. Literature review was conducted using Medline, ProQuest, PubMed, and Blackwell databases with key words such as concept analysis, patient, client, participation, user, customer, and nursing with no time limitation. Since some words such as injury, accident, and road traffic injury drastically reduced the number of articles, they were not included in the search. A great number of articles up to 2016 were evaluated. Articles other than those from the databases were manually searched and are mentioned in the references section. Iranmedex is used to browse domestic articles, from which one by Rafi'ee et al [22] was used for explanation of the meaning. A total of 110 articles were found; the full text of some of which were not available. After reviewing, those articles were chosen that paid attention to the definition and conceptual meaning, among which similarities and differences were studied. Each related article was studied, and those not related were omitted. Finally, related articles were separated from relevant ones, which were used according to the reference section of this very essay.

\section{Fieldwork stage}

It aims to strengthen and refine the concept formed in the previous stage; it overlaps with the first stage from the time point of view and focuses on experimentality. This stage uses quality data gathering to better analyze the concept. In fieldwork stage, because of the importance of the concept, sampling was done from the orthopedic victims of traffic accidents and those closely involved in nursing care of them. Since collaboration in care and mobility rehabilitation is an interactive phenomenon between patients and nurses, and various studies indicate that the patients' and nurses' viewpoints may differ, both the victims and the nurses were sub-structurally interviewed to gather data. Nursing care of traffic victims is specifically done in hospitals. For this purpose, post ICU and surgical wards of the army hospitals were used to collect structural samples, and those victims who were conscious were chosen.

The criteria for participants were: 1. Being hospitalized for at least three days; and 2. Having non-medical limits for an interview, and personal interest. Patients were chosen from both genders, with different levels of education, and orthopedic injuries of different degrees in order to get maximum variability. It took 11 months from Tir
1392 (July 2013) to Khordad 1393 (May 2014). A guideline for the semi-structured interview was prepared in accordance with existing studies, and introducing the head nurse, with time periods of 30-45 minutes, depending on the ability of respondents, 7 traffic accident victims with orthopedic injury and 3 nurses (one from post ICU, and two from surgery) involved in the same patients' nursing care were interviewed.

Interviews continued till there was no new code, and data saturation was done after 10 interviews. Participants signed an informed consent. In the interview, patients were asked about the role of injury in nursing care and mobility rehabilitation, patients' participation in mobility rehabilitation, and effective factors. Interviews were recorded by respondents' permission and after listening to 2-3 times, they were transcribed. The data were analyzed using MAXODA software for groups and categories and content analysis with continuous comparison. Because content analysis is a method to investigate the symbolic meaning of messages with a flexible method in analyzing the text and it is used in qualitative research, it acts as a research technique including professional methods in processing data to data reduction and data construction [23].

The inductive techniques of this approach are used whenever there is not enough knowledge about a phenomenon. Researcher's overall understanding of information and its organization, open coding, categorization, and summarization are some steps of this approach, all of which observed in this very study. Each interview was coded by first reading the text several times to get the overall idea, and then each part was separately titled, and notes were written in the margins. The notes were read twice and the important titles were used to describe aspects of the concept; then the obtained titles were categorized. Similar categories were put next to each other into a bigger category. Each category was given a specific name. It continued logically and possibly till bigger categories to cover aspects of the subject, which finally resulted in four final categories.

As a result, the key features of the concept related to collaboration in caring for traffic accident victims with orthopedic injuries were identified according to the data. Participating patients' and nurses' names are not mentioned to honor their privacy. In order to increase the accuracy and robustness of data, this researcher was continually present in the field and deeply involved in data collection. Additionally, primary extracted codes presented to the respondents were rechecked and recorrected according to their suggestions. In the end, final 
results of the study were evaluated by two professors at the nursing school to increase the reliability and accuracy of the study.

\section{Results}

\section{Theoretical stage}

The term collaboration which has frequently been mentioned in the literature of health system [15], is useful and inspiring, and at the same time an intriguing [16] and challenging [17] concept. Collaboration denotatively emphasizes on involvement and participation which points to sharing in common with others [16]. Collaboration is a conscious, active, free, and responsible action which is necessary for improvement of any society [15]. Studies in the field of health have indicated that collaboration has been considered in most health care decisions, which should be valued in order to achieve the desired results. However, the existence of different terms and words in this field such as involvement, partnership, participation, together with those such as client, consumer, or user confirms that there is no clear definition for it. According to Gaboury and Doss, the concept of collaboration has not yet been fully understood and operational $[23,24]$. In an analytical study by Brownlea, engaged or permit to be engaged in decision-making, giving services, or even in the simplest case of being consulted in a particular topic can all be considered as the concept of collaboration.

Mc Ewen believes that collaboration of patients in health care ensures implementation of all activities set by care team for health protection and promotion, disease prevention, diagnosis, treatment, patient care, and health restoration. If there is no improvement, this collaboration is to bring better compatibility with disability in all fields of treatment and care. For Holloway, collaboration means to engage people in decision-making and to give them responsibility and control [25]. Saunders emphasizes that collaboration of patients is an active process, which includes the capability of patients in following their daily routine, decision-making from admission in hospital to discharge, and also a range of activities like collaboration of patients in personal care as well as general decision-making for health. He considers collaboration as an active involvement in physical or mental activities of others [25]. WHO defines collaboration as an involvement in a situation and believes that learning and using the knowledge in the scope and sphere of activities are included in the meaning of collaboration [26].

The meaning of collaboration is not mentioned specifically in traffic injuries for care and mobility rehabilita- tion, and a separate definition for it is not given here. To minimize traumatic complications and disability, it is therefore necessary for these patients with traffic injuries to have comprehensive collaboration for rehabilitation and mobility care in the shortest time. The object of collaboration for this group of patients is to make them capable enough to live their everyday life independently. Even though the concept of collaboration is mentioned in the philosophies and viewpoints of many health organizations, it is still not definitely and clearly defined in care system and is so far a complicated concept [16].

There are a number of studies about collaboration of patients and effective factors of it, which may be of great help in clarifying the dimensions and features of the concept in care and mobility rehabilitation of patients with traffic injuries. In a study by Clayton, it was shown that the collaboration of patients improves decision-making, quality of life, and retains their sense of power and capability [24]. Biley relates collaboration of patients to the treatment and care decision-making to organizational structure, as well as patients' knowledge and willingness [27]. Biley found ways that help collaboration of patients, and added other factors such as knowledge, acceptance, and patients' agreement to his previous factors [28]. Ashworth in a phenomenological study on collaboration of patients for caring defines it as patients' acceptable and accessible knowledge, their emotional and motivational agreement on the subject with others, their belief in desirable cooperation, and their lack of sense in individual identity threats [29].

In a study on collaboration of patients in decision-making for discharging, Jewell considers the conversation between the patient and the nurse to inform the patient as an active collaborator, to grow sincere relationship between nurse and patient, respect for the patients' rights, attention to individuality of the patients. He also defines collaboration as putting patients at the center of all care plans and decisions. He believes that the practical component of collaboration of patients is in nursing process, and consideration of what a patient needs for discharging and self-caring after that. He emphasizes on the benefit of engaging in activities as a feature in collaboration [30].

Flynn in his study about empowerment of AIDS patients, defines collaboration in caring as a process through which the family manages the additional needs and reduced resources, and at the same time it recognizes that it is necessary to change to return the functional and well-being stability of the family [31]. Cagle in a grounded theory study on diabetic patients introduced collaboration as providing the necessary resources in 
terms of information, time needed for communication, financial, and patients' willingness to utilize these resources, whose consequence will be to empower the patients to be able to take decisions about their care [32].

Wellard in a qualitative study of collaboration in special and acute wards includes equality, negotiation, and responsibility in collaboration, in which the senses of controlling and responsibility are important features of collaboration, because he considers collaboration is something similar to sharing information, ideas, and power of decision-making. He believes that the collaboration should not be limited to sharing in clinical decisions; in general, engagement with others in daily aspects of caring while being in hospital is the real meaning of collaboration. He has of course considered other dimensions and specifications of different cultures in the context collaboration in caring [33].

Eldh phenomenologically studied the collaboration of patients with chronic heart disease and found that trust, understanding, and recognizing patients' own responsibilities are some of the specifications of collaboration to make a strong nurse-patient relationship, which finally ends in a sense of being understood and being respected for the patient. He had another study to complete his previous one with the same subject and added equality in relationship, accepting patients' responsibilities, accountability, and being taken into account to the previous features of collaboration whose results would be patient asking questions, gaining information, and paying attention to his/her individuality. In this study, the main feature of collaboration is the shared information and knowledge [15].

Eldh in his another study of necessary condition for collaboration of patients in health care emphasized that relationship, negotiation, conversation between the nurse and the patient, agreement on clearer roles of each, and explanation of collaboration levels are the major conditions of collaboration [17]. Tutton implicated the concept of collaboration in decision-making, patients' conditions, and patients' personalities. In his study on elderly patients, he defines collaboration as a dynamic process which changes over time and completes the task of nurses and care providers. This process occurs while facilitating, participating, and understanding occur; collaboration is the process of communication with the patient and it can be a basis for this relationship. Findings of this study reflect the fact that caring the patients with severe disability in communication makes the collaboration really difficult [16]. Stewart and Tutton have both stressed on collaboration as mutual connection $[16$,
24]. Sahlsten knew interpersonal techniques, therapeutic approach, focusing on the source, and the opportunity to influence, are some of the features of collaboration. These features promote functional relationship with the patients, cause deliberate dialogue to exchange knowledge and information, and bring the opportunity to the patients [34]. According to Doherty, collaboration in caring is a behavior dependent on social context and structure of the health system, which strengthens awareness among the patients through effective and efficient relationship [35].

Patient oriented care giving with collaborative principle can be considered as an example of a holistic approach to nursing care. Although taking care of patients is the main task of nurses, they can understand the patients' distress due to lack of enough knowledge and lack of responsibility towards the patients. However, nowadays, meeting the information needs, information exchange, knowledge negotiation and agreement tailored to the needs of the patients are the major and basic part of physicians' and nurses' responsibilities. Patients and their family members are considered as an inseparable dyadic unit. Therefore, all nurses have to keep in mind the active involvement of the patients and their family members while planning for nursing the patients.

Literature review of the all related articles suggested that it is not possible to present a single definition of collaboration. Therefore, after combining the definitions discussed here, it may be said that: Collaboration of patients in rehabilitation and mobility care exists that the patients' active involvement and taking responsibility due to information exchange, negotiation, agreement, and knowledge consistent with the needs and moods of the injured. It is based on the knowledge and art of the care providers in a mutual interaction between the nurse and the patient for preservation and promotion of health, induction of a sense of control over the situation and responsibility in the patients. The patients consent with such an involvement and become empowered in order to be independent.

\section{Fieldwork stage}

In this stage, 7 traffic accident victims with orthopedic injuries and 3 nurses (one post ICU nurse, two surgery nurses) engaged in patient care were interviewed. The main questions were: Will you please explain about the cares you receive here? Can you tell me what is important in nursing care? Have you heard about collaboration in caring? What's your idea about it? Can you give me an example? In addition, some probing questions were 
Table 1. Categories and subcategories extracted from collaborative approaches in caring and mobility rehabilitation of the injured in traffic accidents

Organizational Factors to Exchange Information and Knowledge to Provide Independency
Correct informative performance of care providers
Health system and medical education responsiveness
Informative connection and field providing
Professional strategies usage
Promoting Sense of Responsibility in Patient
Encouraging patient to take self-care
Following treatment
Empowering the Patient for Health Promotion
Coping with disability and physical limitations
Avoiding social isolation
Mutual Trust and Cooperation
Nurse's assessment by the patient
Patient's assessment by the nurse
Increasing Sensitivity for Active Engagement to Return to Normal Daily Life
Providing proper and suitable information related to coping with disability
Stressing the collaboration awareness
Ensuring the collaboration

used to clarify the answers given by participants in the interview. Qualitative content analysis method was used to extract 87 primary codes from the interviews and later changed to categories and subcategories by reduction process in categorization. Interviews were transcribed word by word for analysis, and the text was read and reread several times to get the sense of the data. The text obtained from the interviews was divided into condensed semantic units. After abstracting and labeling condensed semantic units, they were arranged in categories and subcategories according to their similarities and differences. Content analysis of the interviews revealed that respondents had mentioned some main topics which were put in some main categories. Categories and subcategories are shown in Table 1. The average age of participants in this study was 49.1 years and the average length of stay for patients hospitalized was 6.24 days. Here the findings of theoretical stage and fieldwork stage are compared whose results will be mentioned in the following section.

\section{Discussion}

The participants in this study wanted to explain their understanding of the concept of collaboration. In both theoretical and fieldwork stages, the implicit and explicit outcomes and results showed that some of the most important and influential factors on collaboration of patients in mobility care are organizational structure, patients' level of knowledge, and patients' willingness for collaboration in caring [36]. The meaning of collaboration in mobility care is divided into five categories: "organizational factors to exchange information and knowledge to provide independency", "promoting sense of responsibility in patient", "empowering the patient for health promotion", "mutual trust", "increasing sensitivity for active engagement to return to normal daily life".

In the case of "organizational factors to exchange information and knowledge to provide independency" a participant (patient 3) said: in the ward I asked them if it's necessary to have surgery after having hung all the weight on my feet. They didn't tell me at all, when the doctor will come for operation. Why should I stay fasting if it's not clear when the doctor comes? What will be my problems after surgery? Is there any? Isn't at all? ... What should I do after surgery? I asked whomever, no answer at all. Another participant (patient 1): When I asked my physiotherapist about the number of sessions to be enough, he put a sour face and told me to ask my nurse. Asking the nurse doesn't answer my question. She said as many as your doctor prescribes.

A participant (patient 6) mentions about "responsiveness of the health system and medical education" that $O k$, it's crowded here and there are lots of patients in the ward, but the hospital has to answer our questions in 
relation to our mobility problems after my traffic accident and the only problem now is not shortage of nursing staff, because these existing nurses, too, cannot answer my questions in relation to resting time and mobility after my operation, they gave me a booklet, no one can get anything out of it; It needs somebody to translate it. And about giving proper treatment information another participant (patient 4) declared that: Whomever I ask what to do to get better soon to be able to walk, and to have my bone repaired.... They just say it depends on you.... Can't they explain it???? What should I eat???.

About informative connection and field providing, a participant mentioned: If the nurse looks into your eyes, or when redressing your foot after surgery, she explains you some points or some information about your mobility or your useful eating, this eye contact together with those information can be of great help to you, if the nurse open the relation or if help you with emotional support, it will help the patient to try to return to normal life, and even if there is some disability, the patient can accept it better. And in the case of professional strategies another participant (nurse 3) explained: About the foot position after major surgeries such as fractures in shank or hip, basically, our nurses are only limited to a pamphlet and they never explain the importance of foot both from aching point of view and from reducing edema in the patient's own language. That's why most patients in orthopedic sections are very nervous because of the pain they feel and all the time demand for some soothing or drug for their relief. This words may seem very simple and commonplace for us, the nurses, but they are really useful to the patient... .

Participants described collaboration in mobility care according to "organizational factors to exchange information and knowledge to provide independency" as a way to eliminate fear, uncertainty, and ambiguity from the process of mobility care caused by care providers. Orem believes that enough knowledge and information about ambiguities help the patients to have empowered and informed choice. In order to obtain such knowledge, the patients need adequate health literacy; proper, available, and reliable information; and enough proficiency for utilizing health resources. Gaining insight and information is a tool to gain independency and help the patients to learn whatever they need for self-care [36]. The first category in this study is consistent with Orem. According to the results obtained from this study, low quality of organizational factors in exchanging information could not attain independency in the injured. They mentioned low level of relationship between the patients and the care givers. Care givers were mostly focused on treatment aspects of caring which ignored the patients".

Psychosocial needs, and accordingly less collaboration of the injured patients in mobility care. This category did not get enough attention in previous studies. It has been found from both stages in this study that the collaboration of patients with traffic injuries would have some positive effects such as mutual relation of the nurses and the patients [16], increase in the sense of control and responsibility in the patients [33], patients' selfempowerment [31], improvement in decision-making and maintaining a sense of power, and as a result promoting life quality [24] of patients with traffic injuries. Ohare, Walls, and Murphy reported that understood social support has a direct effect on health similar to that of exchanging information and knowledge on providing independency, and produces a desirable mental situation [37]. The key to collaboration pattern may be a mutual relation together with trust because informative support and patients' sufficient support while in hospital improve their self-confidence [38]. This is a key which can open all the locks on health systems, and on a large scale, all the locks on human procedures.

From the category "promoting sense of responsibility in patient" two subcategories were extracted. A participant said about encouraging patient to take self-care: It was terrible when the nurse told me I had to do exercise just after my foot had a surgery, but she gave me a pamphlet and showed me pictures of isotonic exercises while the foot was still plastered, then I got what she meant. Another participant mentioned: to believe in rehabilitation and care by the patient in is an important factor which helps the patient accept the information and knowledge of the nurse and to pay attention to whatever is written in the booklet. And a nurse about following treatment said: Not only the physician but also all the other members of the care team such as the nurse, the physiotherapist, and the occupational therapist have to advise the patients to be careful not to put their weight on their operated foot, and to use crane or walker, and also recommend to do hydrotherapy and walking in the water which can help them to return sooner to their pre-injury status.

Encouraging patients to take self-care and following treatment are emphasized in the category "promoting sense of responsibility in patient". Collaboration is defined by WHO as engagement of a person in his/her life realm, which may include a patient's admission to the hospital to the end of his/her discharge period [35]. 
According to Orem theory, for an individual to do selfcare, before anything else, it is important to have motivation and enough willingness. The motivation, itself, is the result of several components, the first of which is the meaning of health for an individual. Accepting and expanding the meaning of health from just physical point of view to the areas of intelligence, emotion, psychology, social, and communication forms a new landscape and insight in the person, which changes his/her understanding of health and brings the need for self-care [36].

The next stage relates to the concepts of "existence value" and "self-image", i.e. whether a person believes his/ her existence of such a value to involve in a conscious effort to maintain and promote his/her health. One's belief system and values have a great role in this context. Patient's previous experiences about whether he/she was successful in health realms and behavior changes, experiences of disease and being not healthy are effective on his/her self-efficacy, and self-care [31]. According to Orem theory, the support from society has relation to the person's estimation of success with his/her motivation for self-care. As a person goes towards those things in which one can be successful, understood self-efficacy has an important impact on patient's motivation for self-care [36].

About coping with disability and physical limitations in the category of "empowering the patient for health promotion" a participant said: If nurses talk in a language we can understand and give us the literacy we need to cope with our new situation, namely to have a positive and good feeling, one can do whatever is necessary. But you can't see much of it in our hospitals. That the patient knows not to stand on him/her own feet is not the end of the life. About avoiding social isolation, as a sub-category of empowering the patient for health promotion, a nurse participant mentioned: When orthopedic patients with mobility problems which make them not to move as before leave here, since there's no supporting systems in our health system, became stay-at-home, and this may cause them physical and psychological problems out of their body disability. With some small suggestions, such as short walking, even for half an hour, with cane or walker, even if they feel ache, will help both their foot muscles and their blood circulation in their feet to lessen the edema to sooner stand on their feet, and also gain a better mood".

In reviewing the third category of the study, collaboration in mobility care means "empowering the patient for health promotion". The patients feel empowered when they may have consciousness and powerful choice [31] which will come, according to Orem theory, after bringing suitable motivation for self-care in patients [36].

Orem believes that in order to have consciousness and powerful choice, a person has to be able to act effectively, which is called "self-efficacy". Such a capability comes from "understood control" and "self-image". "Understood control" is a sense of controlling things related to health area, and the share one has in his destiny; and "self-image" means a set of thoughts and feelings one has about oneself [34]. Self-efficacy is, in a way, specific form of the belief; an individual's belief in his/ her capability in controlling to have his/her experiences and successes. After knowledge acquisition and self-efficacy, an individual acquires the necessary qualifications for evaluating decisions and proper implementation.

Collaborative decision-making is one of the major principles of collaboration, and leads to informing a patient about care procedure which will be followed by patient's collaboration in care taking [14]. All these qualifications can be acquired and learned through organized and specified programs of life skills training in addition to life experiences and family environment [35]. Finally, an individual with motivation, knowledge, control, self-efficacy, and sufficient qualifications needs social supports to be able to change to health behavior. This support may include necessary provisions for acquiring knowledge, motivation, and skills; and encouraging and developing alternatives for choosing health behaviors [35].

It is important to mention that a facilitating and supporting environment influences acquiring and strengthening all other three components of knowledge, self-efficacy, and qualification; and it is also influential in need for self-care and contextual factors. The role of social support network including family and health professionals (physicians, nurses, ...) becomes clearer here [36]. These findings are the same as those in studies by Pryor and Buzio and McKinley in that empowering patients and independency obtained from it increases the collaboration of patients and leads to living an independent life [39, 40].

In the case of mutual trust and cooperation, most of the participants believed in good relation that will grow confidence from both sides. The importance of establishing Interaction and efficient relationship was mentioned by most patients. From their point of view, failure to communicate, make them feel being forgotten and ignored. Patients announced respectful and honorable relationship, especially in the beginning of their hospitalization as relaxing and trust factors. Though the patients pointed to the importance of communication with them, they 
Table 2. The specifications for the concept of collaboration in mobility care for patients with traffic injuries in theoretical and fieldwork stages

\begin{tabular}{|c|c|}
\hline Theoretical Stage & Fieldwork Stage \\
\hline Shared information and knowledge & $\begin{array}{l}\text { Organizational factors to exchange information and knowledge } \\
\text { to provide independency }\end{array}$ \\
\hline Giving the patient a sense of control and responsibility & Promoting sense of responsibility in patient \\
\hline Benefiting from engaging actively in physical and mental activities & Empowering the patient for health promotion \\
\hline Mutual relation and negotiation & Mutual trust and cooperation \\
\hline \multirow[t]{2}{*}{ Improving the sense of self-help to recover sooner } & $\begin{array}{l}\text { Increasing sensitivity for active engagement to return to normal } \\
\text { daily life }\end{array}$ \\
\hline & $\begin{array}{l}\text { Hlealth in } \\
\text { Emergencies and |D]isasters [Oluarterly }\end{array}$ \\
\hline
\end{tabular}

were really modest and satisfied with least communications. They were happy with simple greetings, and they believed collaboration in mobility care indebted to confidence under the shadow of useful and good relationship, where they would feel the kind presence of nurses next to them. A patient said: A nurse is here, when she comes in the morning, she listens to the patients'words and complaints and answers all the questions. She asks everybody if slept well enough. I've even saw her explaining about the side effects of drug injection, then the patients' wouldn't insist on injecting more. When she's on her shift, I'm not worried about anything. I fully trust her and I feel she keeps an open eye for me and everyone else. She tries her best to help us to walk as soon as possible.

In reviewing the fourth category, participants mentioned that a proper and mutual treatment relationship is a way for collaboration in mobility rehabilitation. Treatment communication is a condition or interaction between the nurse and the patient which is of vital importance in mobility rehabilitation [15]. Nurse-patient relationship leads to patients' support and understanding, and helps patients accept their previously non-existing injury which is now in this new situation, and causes mutual trust under such a relationship. Mutual understanding in roles and responsibilities with support of mutual trust is one of the important factors of collaboration in mobility care [34].

Nurses' knowledge and qualification are useful in establishing effective treatment relationship. For example, listening to patients, paying attention to their priorities, indulging in honest talking, and responding to their expectations result in confidence building among patients [36]. Devoting time for treatment relationship also leads to facilitates the nurse-patient interaction, recognizes the patients' needs, effective care, and meet the patients' treatment needs [39]. Communicating with the patient is such an important aspect of collaboration in mobility care that without communication it is impossible for the nurses to do some tasks such as physical care, emotional care, and providing information. Therefore, in this context it is also important to pay attention to the nurses' problems such as shortage of time, shortage of manpower, as well as shortage of interest and motivation [35].

Finally about the category "increasing sensitivity for active engagement to return to normal daily life", most of the participants believed that their collaboration in mobility rehabilitation helped them increase their sensitivity to return to their normal life as soon as possible. One of the participants explained: When the treatment team talk to me clearly and frankly about what I can do to get better sooner and to be able to walk, I don't see my recovery and standing back much far, and I feel more encouraged to better bear my physiotherapy or more seriously continue my exercise sessions despite the pain I feel. Another patient indicated: A very ill patient was taken to ICU last night. I asked the nurse about it. Since the nurse told me if I don't walk with my cane or a companion, a clot may move from my leg to make everything worse or even to kill me. Despite the pain I try to walk or at least move my leg while on bed.

Participants in the study believed that collaboration in mobility rehabilitation helps increase sensitivity for active engagement to return to normal life. It means that the participants described achieving self-care in the shadow of improving health awareness, and increasing sensitivity to return to normal life, as an effort to reduce disease-related vulnerability and to promote life quality. It was necessary for them to cope gradually with their problem and the disability caused by the injury, and increasing their sensitivity to return to their normal life that caused a mutual collaboration for desirable mobility rehabilitation. 
The mobility rehabilitation is an indicator for effective adaptation to accept the patients' present condition and as a result develop willingness for collaboration in caring. Findings in the studies by Frazen and Peden show that the victims injured by traffic accidents are in doubt and ambiguity about the possibility of their health recovery and they do their best to return to their normal life, although they are in great need of support and security which should be given by their treating team, especially the nurses [38, 41]. By maintaining human communication, certified nurses help the patients find their courage and capability to adapt to their critical illness.

Findings of this very study indicate that not internalizing holistic approach, and not emphasizing on patient oriented caring, bring about the patterns which result in fewer collaborations by the patients. The treatment team members, who are the results and outcomes of medical educations at the universities, are not sensitive enough to the actual needs of the patients, and mostly do treatment according to their own wishes. Of course the arguments and obstacles raised by the personnel in relation to collaborative, structural and organizational limitations are notable. However, if there is a belief in usefulness of collaboration of patients in caring, solutions must be there to overcome the obstacles to provide better conditions to the patients and their family. At the same time, it seems most of these arguments do not have logical and scientific basis, and are just based on organizational presuppositions.

\section{Dimensions of the concept}

A comparison of different dimensions of the concept, namely, collaboration in mobility care for patients with traffic injuries between two stages (theoretical and fieldwork) is presented in Table 2. This comparison indicates that most of the components were consistent in theoretical and fieldwork stages.

\section{Conclusion}

This report attempted to fill the empty place of uncertain understanding of patients and care providers in relation to the meaning of collaboration in mobility care. The findings of this study showed that it is necessary to clarify the patients' ambiguities, improve their health, knowledge, literacy, empower the injured, and make a treatment relationship to achieve a mutual trust, which is most important foundation for collaboration in mobility care. According to the findings, it is imperative to pay attention to promote the sense of responsibility with an emphasis on self-care programs.
The outcome of this study can help in planning suitable strategies regarding the patients' viewpoints and expectations in achieving collaboration in mobility care, and as a result, developing caring quality and increasing patients' satisfaction of the nurses, managers, and all decision-makers in the realm of health. Since the idea of collaboration of patients is considered as the foundation and basis of new paradigm of nursing, it is necessary for the managers to devote time and budget. It is also important to eliminate the existing obstacles to achieve collaboration in mobility care of patients with traffic injuries, which would change the caring paradigm and make the nurses familiar with the pattern of collaboration based on the patients' expectations.

One of the limits of this study was that the patients were in army hospitals, which may cause some different experiences because of the contact base concept of this study. More studies are suggested to better recognize the understanding and experiences of different groups of patients (like critical patients, hospitalized patients in special parts and operated patients) to make the concept clearer. Future studies could aim at planning for collaborative tools in caring according to the viewpoints of hospitalized patients who are conscious and capable of cooperation. Finally, regarding the role of nurses believing in collaboration in care and patients' cooperation in treatment, it is recommended to study with greater sample numbers in future.

\section{Acknowledgments}

Tehran Traffic Police Research Center has financially supported the present paper. We are deeply thankful to those patients and nurses who helped us throughout this study.

\section{Conflict of Interest}

The authors declared no Conflicts of Interest.

\section{References}

[1] World Health Organization. Global status report on road safety 2015. Geneva: World Health Organization; 2015

[2] Afzali S, Saleh A, Seif Rabiei MA, Taheri K. Frequency of alcohol and substance abuse observed in drivers killed in traffic accidents in Hamadan, Iran. Archives of Iranian Medicine. 2013; 16(4):240-2. doi: 013164/ AIM.0010.

[3] Haghparast-Bidgoli H, Khanke H, Jahansson E, Yarmohammadian MH, Hasselberg M. Exploring the provision of hospi- 
tal trauma care for road traffic injury victims in Iran: a qualitative approach. Journal of Injury and Violence Research. 2013 5(1):28-37. doi: 10.5249/jivr.v5i1.195

[4] Bakhtiyari M, Delpisheh A, Monfared AB, Kazemi-Galougahi $\mathrm{MH}$, Mehmandar MR, Riahi M, et al. The road traffic crashes as a neglected public health concern; an observational study from Iranian population. Traffic Injury Prevention. 2015; 16(1):36-41. doi: 10.1080/15389588.2014.898182

[5] Finkelstein EA, Corso PS, Miller TR. The incidence and economic burden of injuries in the United States. New York: Oxford University Press; 2006.

[6] Unicef. Road Traffic Injuries in Iran and their Prevention. A Worrying Picture [Internet]. 2012 [Updated 2012 August 12] Available from: https://www.unicef.org/iran/media_4783. html

[7] World Health Organization. Violence and Injury Prevention and Disability (VIP); Road traffic injuries [Internet]. 2012 [Updated 2012 November 27]. Available from: http:/ / www.who. int/violence_injury_prevention/road_traffic/en/

[8] Marshall SS, Haywood KL, Fitzpatrick R. Patient involvement and collaboration in shared decisionmaking: A review. Oxford: University of Oxford; 2005.

[9] Cahill J. Patient participation - a review of the literature. Journal of Clinical Nursing. 1998; 7(2):119-28. doi: 10.1046/j.13652702.1998.00132.x

[10] Millard L, Hallett C, Luker K. Nurse-patient interaction and decision-making in care: patient involvement in community nursing. Journal of Advanced Nursing. 2006; 55(2):14250. doi: 10.1111/j.1365-2648.2006.03904.x

[11] Soberg HL, Bautz-Holter E, Roise O, Finset A. Long-term multidimensional functional consequences of severe multiple injuries two years after trauma: a prospective longitudinal cohort study. Journal of Trauma: Injury, Infection, and Critical Care. 2007; 62(2):461-70. doi: 10.1097/01.ta.0000222916.30253. ea

[12] Patistea E, Siamanta H. A literature review of patients' compared with nurses' perceptions of caring: Implications for practice and research. Journal of Professional Nursing. 1999; 15(5):302-12. doi: 10.1016/s8755-7223(99)80056-8

[13] Sahlsten MJ, Larsson IE, Sjöström B, Plos KA. An analysis of the concept of patient participation. Nursing Forum. 2008; 43(1):2-11. doi: 10.1111/j.1744-6198.2008.00090.x.

[14] Russell AN. How individuals with traumatic injuries manage their lives following a motor vehicle accident crash $[\mathrm{PhD}$ thesis]. Kent: Kent State University; 2008.

[15] Eldh AC, Ehnfors M, Ekman I. The phenomena of participation and non-participation in health care -experiences of patients attending a nurse-led clinic for chronic heart failure. European Journal of Cardiovascular Nursing. 2004; 3(3):239_ 46. doi: 10.1016/j.ejcnurse.2004.05.001

[16] Tutton EMM. Patient participation on a ward for frail older people. Journal of Advanced Nursing. 2005; 50(2):143-52. doi 10.1111/j.1365-2648.2005.03373.x

[17] Eldh AC, Ekman I, Ehnfors M. Conditions for patient participation and non-participation in health care. Nursing Ethics. 2006; 13(5):503-14. doi: 10.1191/0969733006nej898oa
[18] Efraimsson E, Sandman PO, Hyden LC, Rasmussen BH. Discharge planning: "fooling ourselves?"--patient participation in conferences. Journal of Clinical Nursing. 2004; 13(5):562-70. doi: 10.1111/j.1365-2702.2004.00900.x

[19] Parker JM. The art \& science of nursing. In: Daly J, Speedy S, Jackson D, editors. Context of Nursing: An Introduction. Amsterdam: Elsevier; 2000.

[20] Daly J, Speedy S, Jackson D, Lambert V, Lambert C. Professional nursing: Concepts, issues and challenges. New York: Speringer; 2005.

[21] Schwartz-Barcott, D, Kim HS. An expansion and elaboration of Hybrid model of concept development. In: Rodgers BL, Knafl KA, editors. Concept Development in Nursing: Foundation, Techniques, and Application. Philadelphia: W.B. Saunders Company; 2000.

[22] Salsali M, Mohammadpoor A, Fakhrmovahedi A. The methods of concept development. Tehran: Tohfe-Boshra Publication; 2006

[23] Rafii F, Soleimani M, Seyed-Fatemi N. [Concept analysis of participation of patient with chronic disease: use of hybrid model (Persian)]. Iran Journal of Nursing. 2010; 23(67):35-48

[24] Doss S, DePascal P, Hadley K. Patient nurse partnership. Nephrology Nursing Journal. 2011; 38(2):115-125. PMID: 21520690

[25] Gaboury I, Bujold M, Boon H, Moher D. Interprofessional collaboration within Canadian integrative healthcare clinics: Key components. Social Science \& Medicine. 2009; 69(5):70715. doi: $10.1016 /$ j.socscimed.2009.05.048

[26] Cahill J. Patient participation: A concept analysis. Journal of Advanced Nursing. 1996; 24(3):561-71. doi: 10.1046/j.13652648.1996.22517.x

[27] World Health Organization. International classification of functioning, disability and health (ICF) [Internet] 2003 [Updated 2003 September 12] Available from: http://www.who. int/classifications/icf/en/

[28] Biley FC. Treatment and care: Patient participation in decision making. Senior Nurse. 1989; 9(10):23-24

[29] Biley FC. Some determinants that effect patient participation in decision making about nurse care. Journal of Advanced Nursing. 1992; 17(4):414-21. doi: 10.1111/j.13652648.1992.tb01924.x

[30] Ashworth PD, Longmate MA, Morrison P. Patient participation: Its meaning and significance in the context of caring. Journal of Advanced Nursing. 1992; 17(12):1430-39. doi: 10.1111/j.1365-2648.1992.tb02814.x

[31] Jewell SE. Patient participation: What does it mean to nurses? Journal of Advanced Nursing. 1994; 19(3):433-38. doi: 10.1111/j.1365-2648.1994.tb01104.x

[32] Flynn MB, McKeever JL, Spada T, Gordon-Garofalo V. Active client participation: An examination of self-empowerment in HIV/AIDS case management with women. Journal of the Association of Nurses in AIDS Care. 2000; 11(3):59-68. doi: 10.1016/s1055-3290(06)60276-8

[33] Cagle, CS. Practitioners' actions inhibited patient participation in self care decision making. Evidence-Based Nursing. 2002; 5(2):62. doi: 10.1136/ebn.5.2.62 
[34] Wellard S, Lillibridge J, Beanland C, Lewis M. Consumer participation in acute care settings: An Australian experience. International Journal of Nursing Practice. 2003; 9(4):255-60. doi: 10.1046/j.1440-172x.2003.00429.x

[35] Sahlsten MJM, Larsson IE, Sjöström B, Plos KAE. An analysis of the concept of patient participation. Nursing Forum. 2008; 43(1):2-11. doi: 10.1111/j.1744-6198.2008.00090.x

[36] Doherty C, Doherty W. Patients' preferences for involvement in clinical decision-making within secondary care and the factors that influence their preferences. Journal of Nursing Management. 2005; 13(2):119-27. doi: 10.1111/j.13652934.2004.00498.x

[37] Pryor J, Buzio A. Enhancing inpatient rehabilitation through the engagement of patients and nurses. Journal of Advanced Nursing. 66(5):978-987. doi: 10.1111/j.13652648.2009.05237x

[38] Ohare MA, Walls L, Murphy GC. Social support Paris predict daily functioning following traumatic spinal cord injury: An exploratory study. The Open Rehabilitation Journal. 2011; 4(1):51-58. doi: 10.2174/1874943701104010051

[39] Kneafsey, R. An Exploratoration of the contribution of nurses and care assistants to patients' mobility rehabilitation [PhD thesis]. Birmingham: University of Birmingham; 2012

[40] Franzén C, Björnstig U, Jansson L. Injured in traffic: Experiences of care and rehabilitation. Accident and Emergency Nursing. 2006; 14(2):104-10. doi: 10.1016/j.aaen.2006.01.003

[41] McKinley S, Nagy S, Stein-Parbury J, Bramwell M, Hudson $\mathrm{J}$. Vulnerability and security in seriously ill patients in intensive care. Intensive and Critical Care Nursing. 2002; 18(1):2736. doi: 10.1054 /iccn.2002.1611 
